\title{
STUDY OF EFFECT OF LIGNOCAINE IN PREVENTION OF PAIN AND WITHDRAWAL MOVEMENTS AFTER INTRAVENOUS ROCURONIUM INJECTION
}

\author{
Adim Prasai and Abha Prasai
}

Department of Anaesthesia, Nepal Medical College Teaching Hospital, Attarkhel, Gokarneshwor-8, Kathmandu, Nepal

\begin{abstract}
Rocuronium bromide is an amino-steroidal neuromuscular blocking drug frequently used in anesthetic practice. It causes intense discomfort and pain at the site of injection and was reported by $50-80 \%$ of patients. Use of local anesthetic agents have been widely supported for prevention of pain. We studied the effect of lignocaine in prevention of pain during rocuronium injection in 160 patients. Preservative free lignocaine at a dose of $1 \mathrm{mg} / \mathrm{kg}$ was given intravenously after applying tourniquet. Venous occlusion was released after one minute and $0.6 \mathrm{mg} / \mathrm{kg}$ of rocuronium was injected. Pain score was recorded according to a 5-point likert scale of pain and withdrawal was graded with 4-point scale. Total number of female patients was $96(60 \%)$ and male patients was 64 (40\%). Among them, 131 (81.9\%) fell in ASA I and remaining 29 (18.9\%) in ASA II. One hundred and thirty-eight (86.3\%) patients did not complain of pain when asked. Mild and moderate pain was seen in $17(10.6 \%)$ and $4(2.5 \%)$ patients respectively whereas 1 $(0.6 \%)$ patient had severe pain. Wrist movement was noted in $10(6.25 \%)$ patients and remaining $150(93.75 \%)$ had no withdrawal movement during the injection of rocuronium. Pre-treatment with intravenous lignocaine helps in prevention of pain and withdrawal movements caused by intravenous rocuronium injection in patients.
\end{abstract}

\section{KEYWORDS}

Rocuronium, Lignocaine, Pain, Prevention

\section{CORRESPONDING AUTHOR}

Dr. Adim Prasai,

Lecturer

Department of Anaesthesia,

Nepal Medical College Teaching Hospital,

Attarkhel, Gokarneshwor-8, Kathmandu, Nepal

Email: frennadii@gmail.com

Orcid No: https://orcid.org/0000-0002-2446-5289

DOI: https://doi.org/10.3126/nmcj.v23i2.38547 


\section{INTRODUCTION}

Rocuronium bromide is an amino-steroidal neuromuscular blocking drug and is characterized by rapid onset and intermediate duration of action. ${ }^{1}$ It is frequently used in anesthesia practice; however it causes intense discomfort at the site of injection in conscious patients. ${ }^{2-4}$ Discomfort and pain were reported by $50-80 \%$ of patients when they were administered with a sub-paralysing dose of rocuronium. ${ }^{3,5}$ As the pain due to rocuronium injection is early in onset with short duration and no recurrence during repeated injection, it has been suggested that this pain is associated with local irritant effect, thus, local anesthetic effect of lignocaine might be useful for preventing this pain. The aim of our study is to evaluate the effect of pre-treatment with lignocaine in preventing pain and withdrawal movements caused by intravenous rocuronium injection in patients during induction of general anesthesia.

\section{METHODS AND MATERIALS}

This is an observational study among all patients who underwent elective surgery under general anesthesia in Nepal Medical College and Teaching hospital within a period of past 10 months (March 2020 to Jan 2021). Ethical approval was taken from the institutional review committee (Ref. no.: 036-076/077). After thorough pre-anesthetic evaluation, the procedure was explained to the patients prior to surgery and informed consent was taken. On arrival to Operation Theater, monitoring with electrocardiography, non-invasive blood pressure, and pulse oximetry was started. A suitable peripheral vein was cannulated with (18G/20G) IV cannula via which a crystalloid solution was mounted and free flow through the venous cannula was ensured. The tourniquet was applied $5 \mathrm{~cm}$ proximal to the intravenous cannula and its pressure was gradually increased until cessation of flow of the crystalloid solution. The study drug was injected (2\% lignocaine (preservative free) $1 \mathrm{mg} / \mathrm{kg}$ intravenously) over 5 seconds. Venous occlusion was released after 60 seconds and injection rocuronium was injected at a dose of $0.6 \mathrm{mg} / \mathrm{kg}$ at the rate of $0.5 \mathrm{ml}$ per second. Immediately, the prime investigator asked the patient whether he/she suffered any pain on rocuronium injection and to quantify it if any. The anesthesiologist in-charge was asked to proceed with the induction of anesthesia. Pain score was recorded and the data was collected using pre-designed proforma and analysed in Statistical Package for the SPSS version 16. Point estimate at 95\% Confidence Interval (CI) was calculated along with frequency and proportion for binary data.

\section{Inclusion criteria}

1. Age: $16-65$ years old

2. ASA grade I and II

3. Elective surgeries under general anesthesia who require muscle relaxation

\section{Exclusion criteria}

1. Age $<16 y r s$ or $>65$ years

2. Patient's refusal

3. Allergy to any of the study drugs

4. Chronic pain syndrome

5. Neurological deficit

6. Vascular disease

7. Difficult venous access

8. Infection dorsum of hand

\section{RESULTS}

The total number of cases enrolled was 160 . None of the patients were excluded from the study. All patients were comparable with regards to age, gender and ASA grading. (Table 1). The total number of female patients was 96 (60\%) and male patients was $64(40 \%)$. Among them, 131 (81.9\%) fell in ASA I and the remaining 29 (18.9\%) in ASA II.

One hundred and thirty-eight (86.3\%) patients did not complain of pain when asked. Mild and moderate pain was seen in $17(10.6 \%)$ and 4 (2.5\%) patients respectively whereas $1(0.6 \%)$ patient had severe pain (Table 2). During the study of the withdrawal movement to pain, wrist movement was noted in 10 (6.25\%) patients and movement involving the arm only (elbow/shoulder) and generalized movement or withdrawal in more than one extremity was not

\begin{tabular}{|lc|}
\hline \multicolumn{2}{|c|}{ Table 1: General characteristics } \\
Variables & n (\%) \\
Age & \\
$16-25$ & $38(23.8)$ \\
$26-35$ & $36(22.5)$ \\
$36-45$ & $30(18.8)$ \\
$46-55$ & $36(22.5)$ \\
$56-65$ & $20(12.5)$ \\
ASA & \\
Grade I & $131(81.9)$ \\
Grade II & $29(18.1)$ \\
Gender & \\
Female & $96(60.0)$ \\
Male & $64(40.0)$ \\
\hline
\end{tabular}


Table 2: Assessment of pain during Rocuronium injection

\begin{tabular}{|lc|} 
Assessment of Pain & $\mathbf{n}(\%)$ \\
No pain & $138(86.3)$ \\
Mild & $17(10.6)$ \\
Moderate & $4(2.5)$ \\
Severe & $1(0.6)$ \\
\hline
\end{tabular}

Table 3: Assessment of withdrawal movements during Rocuronium injection

\begin{tabular}{|lc|}
\hline Grade of Withdrawal Movements & $\mathbf{n}(\%)$ \\
No response & $150(93.75)$ \\
Wrist Movement & $10(6.25)$ \\
\hline
\end{tabular}

Table 4: Intraoperative complications

$\begin{array}{lc}\text { Intraoperative Complications } & \mathbf{n}(\mathbf{\%}) \\ \text { No complication } & 154(96.3) \\ \text { Hypertension } & 1(0.6) \\ \text { Hypertension/tachycardia } & 2(1.3) \\ \text { Hypotension } & 2(1.3) \\ \text { Tachycardia } & 1(0.6)\end{array}$

seen in any patient. The remaining 150 (93.75\%) patients had no withdrawal movement during the injection of rocuronium (Table 3 ).

No intraoperative complications were seen in $154(96.3 \%)$ patients. Hypertension was seen in $1(0.6 \%)$, Hypotension in $2(1.3 \%)$, tachycardia in $1(0.6 \%)$ and hypertension along with tachycardia in $1(0.6 \%)$ patients (Table 4$)$.

\section{DISCUSSION}

Rocuronium bromide is a relatively new steroidal non-depolarizing neuromuscular blocking agent characterized by a rapid onset and intermediate duration of action. Its main advantage over other such agents is its rapid onset of action, which may lead to its use as the relaxant of choice when rapid intubation is required. Unlike other aminosteroidal non-depolarizing neuromuscular blocking agents, it does not produce active metabolites. An additional advantage is that it is hemodynamically stable so can be used in high risk patients. However it causes intense discomfort at the site of injection in conscious patients. ${ }^{2,3,4}$ Discomfort and pain was reported by $50-80 \%$ patients when they were administered with subparalysing dose of rocuronium. ${ }^{3,5}$ Even after induction of anaesthesia with intravenous anaesthetic agents like propofol or sodium thiopentone, rocuronium causes hand or limb withdrawal or generalized movement in $85 \%$ of patients which suggests the presence of intense nociception even under anaesthesia. ${ }^{1,6}$ Injection pain or withdrawal movement (IPWM) is characterized by sudden flexion of the wrist and arm after rocuronium injection and lasts 10-20 seconds. ${ }^{7}$ There have been arguments against the necessity of alleviating IPWM based on the lack of convicting data regarding negative patient outcome caused by IPWM. ${ }^{1}$ However, pain on injection and other stressful stimulation during induction of anesthesia have shown to cause myocardial ischemia or bronchospasm. ${ }^{8,9}$ Moreover, a case of pulmonary aspiration caused by rocuronium-induced generalized spontaneous movements has been reported. ${ }^{10}$ In children, the loss of established vascular access and subcutaneous fat tissue thickness require re-cannulation of thin vessels which can be difficult at times. ${ }^{11}$ These observations in previous studies emphasizes the importance of attenuating IPWM caused by rocuronium.

In the recent past, we observed the occurrence of sudden grimace and flexion of wrist and arm into which rocuronium was injected. This reaction was seen even when rocuronium was injected after induction of anesthesia with intravenous anesthetic agents. The exact mechanism of pain caused by rocuronium injection is not known, but different mechanisms have been suggested. Pain due to injection of anesthetic agents is perceived by polymodal nociceptors that innervate the peripheral veins. ${ }^{12}$ The pain is more frequent and severe when the drug has non-physiological osmolality or $\mathrm{pH}$ values. ${ }^{13}$ Rocuronium bromide is formulated with sodium acetate, sodium chloride, or acetic acid to produce a solution of $\mathrm{pH} 4$. The acidic $\mathrm{pH}$ of the isotonic and sterile solution of rocuronium can be the cause of pain during injection. It has been reported that pain occurs because of the subsequent release of calcitonin gene related peptide and PGE2 as aminosteroid neuromuscular blockers directly activate $\mathrm{C}$ nociceptors. ${ }^{14}$ Another mechanism of pain is postulated to be the release of local mediators such as histamine and kinins but lack of erythema and warmth in the surrounding tissue after injection makes it unlikely. ${ }^{15}$ Different modalities on prevention of pain on injection of rocuronium have been attempted, including the use of local anaesthetic drugs, ${ }^{1,12,16,17}$ opioids, ${ }^{16,17}$ ondansetron, ${ }^{15,17}$ ketamine, ${ }^{18}$ paracetamol, ${ }^{19,20}$ sodium bicarbonate, ${ }^{21}$ nitrous oxide, ${ }^{22}$ sevoflurane, ${ }^{23}$ and esmolol. ${ }^{24}$ In our study, we used preservative free lignocaine intravenously to prevent the pain after rocuronium injection. As the pain due to rocuronium injection is early in onset with short duration and no recurrence 
during repeated injection, it has been suggested that this pain is associated with local irritant effect, thus, local anesthetic effect of lignocaine might be useful for preventing this pain. ${ }^{12}$ As Cheong et $a l^{5}$ showed that there was a decrease in pain on injection of rocuronium from $77 \%$ to $37 \%$ and $7 \%$ when lignocaine was given before rocuronium at doses of $10 \mathrm{mg}$ and $30 \mathrm{mg}$ respectively, we observed that $17(10.6 \%)$ patients complained of mild pain, $4(2.5 \%)$ complained of moderate pain and $1(0.6 \%)$ patient complained of severe pain during injection of rocurounium after intravenous lignocaine.

Our study demonstrated that 138 (86.3\%) patients did not experience pain which is similar to Binarani et $a l^{19}$ who had commented that eighty percent patients in lignocaine group did not have pain.

Dilution of rocuronium solution and slowing rates was also proposed as effective technique. ${ }^{25,26}$ When intravenous agents are used for managing pain, their administration through the venous occlusion technique increases their efficiency. ${ }^{12}$ The venous occlusion technique is suitable for studying the peripheral action of pretreatment drugs with local effects such as lignocaine, ondansetron or tramadol ${ }^{16}$ but is not useful for drugs that act centrally, such as morphine or fentanyl because it prevents the delivery of drugs to the site where they act. We used the venous occlusion technique in our study and the results showed that the local effect of lignocaine was potent.

No intraoperative complications were seen in 154 (96.3\%) patients. Hypertension, hypotension, tachycardia and hypertension along with tachycardia was seen in some patients. These complications were associated with pain during rocuronium injection and were not seen in patients who did not complain of pain.

Preservative free lignocaine is easily available, cheap and safe to use intravenously. It helps in decreasing the pain as well as for attenuation of complications like tachycardia and hypertension.

The limitation of our study was that we did not have a control or placebo group to which no local anaesthetic was administered. However, we believed that a control group was not necessary, because it is unethical to keep patients devoid of analgesics and previous studies have shown that $50-80 \%$ of patients complained of pain during rocuronium injection. Our result suggests that pre-treatment with intravenous lignocaine helps in attenuating the pain caused by rocuronium injection.

\section{ACKNOWLEDGEMENT}

We would like to express our sincere gratitude to Prof. Dr. Shiba Kumar Rai (Research Director of NMCTH) and Institutional Review Committee (IRC) of Nepal Medical College Teaching Hospital for giving us the permission to carry out the study and Dr. Minani Gurung and Dr. Nischal Dhakal for their support.

\section{Source for this Research Fund:}

\section{Conflict of Interest:}

\section{REFERENCES}

1. Shevchenko Y, Joscon JC, McRae VA, et al. The use of Lignocaine for preventing the withdrawal associated with the injection of rocuronium in children and adolescent. Anesth Analg 1999; 88: 746-8.

2. Dalglish DJ. Drugs which cause pain on intravenous injection. Anaesthesia 2000; 55: 8289.

3. Lockey D, Coleman P. Pain during injection of rocuronium bromide. Anaesthesia 1995; 50: 474.

4. Borgeat A, Kwaistkowski D. Spontaneous movements associated with rocuronium: is pain on injection the cause? Br J Anaesth 1997; 79: 382-3.
5. Cheong KF, Wong WH. Pain on injection of rocuronium: influence of two doses of lignocaine pretreatment. Br J Anaesth 2000; 84: 106-7.

6. Joshi GP, Whitten CW. Pain on injection of rocuronium bromide. Anaesth Analg 1997; 84: 228.

7. Park S. Prevention of rocuronium injection pain. Korean J Anesthesiol 2014; 67: 371-72.

8. Morishima T, Sobue K, Arima H, et al. Profound pain due to Propofol injection triggered myocardial ischemia in a patient with a suspected pheochromocytoma. Anesth Analg 2003; 96: 631 . 
9. Zeidan A. Profound pain due to Propofol injection triggered severe bronchospasm in a smoker- A case report. Middle East J Anaesthesiol 2006; 18: 939-42.

10. Lui JT, Huang SJ, Yang CY, Hsu JC, Lui PW. Rocuronium-induced generalized spontaneous movements cause pulmonary aspiration. Chang Gung Med J 2002; 25: 617-20.

11. Solomowitz BH. Intravenous cannulation: a different approach. Anesth Prog 1993; 40: 20-2.

12. Polat R, Akin M, Keskin G et al. Prevention of withdrawal movement associated with the injection of rocuronium in children: comparison of paracetamol and lidocaine. Turk J Anaesth Reanim 2016; 44: 86-90.

13. Kelment W, Atndt JO. Pain on i.v. injection of some anesthetic agents is evoked by the unphysiological osmolarity or $\mathrm{pH}$ of their formulations. Br J anaesth 1991; 66: 189-95.

14. Blunk JA, Seifert F, Schmelz M, ReehPW, Koppert W. Injection pain of rocuronium and vecuronium is evoked by direct activation of nociceptive nerve endings. Eur J Anaesthesiol 2003; 20: 245-253.

15. Reddy MS, Chen FG, Ng HP. Effect of ondansetron pretreatment on pain after rocuronium and propofol injection: a randomised, doubleblind controlled comparison with lidocaine. Anesthesia 2001; 56: 879-905.

16. Ahmad N, Choy CY, Aris EA, Balan S. Preventing the withdrawal response associated with rocuronium injection: A comparison of fentanyl with lidocaine. Anesth Analg 2005; 100: 987-90.

17. Memis D, Turan A, Karamanlioglu B, Sut N, Pamukcu Z. The prevention of pain from injection of rocuronium by ondansetron, lidocaine, tramadol and fentanyl. Anesth Analg 2002; 94: 1517-20.

18. Kosare SS, Dave NM, Garasia M. Fentanyl or ketamine pre-treatment to prevent withdrawal response to rocuronium. Indian J Anaesth 2017; 61: 350-52.

19. Binarani M, Singh YA, Lairenlakpam DS, et al. Efficacy of pretreatment with intravenous paracetamol and lidocaine on rocuronium injection pain: A randomized, double-blinded, placebo-controlled study. J Med Soc 2017; 31: 99103.

20. Uzun S, Erden IA, Canbay O, Aypar U. The effect of intravenous paracetamol for the prevention of rocuronium injection pain. Kaohsiung J Med Sci 2014; 30: 566-69.

21. Chiarella AB, Jolly DT, Huston CM, Clanachan AS. Comparison of four strategies to reduce the pain associated with intravenous administration of rocuronium. Br J Anaesth 2003; 90: 377-9.

22. Sharma S, Sharma D, Jain A, Jain A. Effect of nitrous oxide on pain due to rocuronium injection: A randomised, double-blind, controlled clinical trial. Indian J Anaesth 2010; 54: $142-6$

23. Na YC, Lee HG, Lee SH, Jang EA, Yoon MH. The efficacy of sevoflurane inhalation alone or its combination with intravenous remifentanil against withdrawal movements on rocuronium injection in children. Korean J Anesthesiol 2014; 67: 373-7.

24. Yavascaoglu B, Kaya FN, Ozcan B. Esmolol pretreatment reduces the frequency and severity of pain on injection of rocuronium. $J$ Clin Anesth 2007; 19: 413-17.

25. Shin YH, Kim CS, Lee JH et al. Dilution and slow injection reduces the incidence of rocuronium induced withdrawal movements in children. Korean J Anesthesiol 2011; 61: 465-9.

26. Tuncali B, Karci A, Tuncali BE et al. Dilution of rocuronium to $0.5 \mathrm{mg} / \mathrm{ml}$ with $0.9 \% \mathrm{NaCl}$ eliminates the pain during intravenous injection in awake patients. Anesth Analg 2004; 99: 740-3. 